\title{
Report of the 16th Annual International Scientific Conference of the Montenegrin Sports Academy
}

\author{
Ivana Bavcevic ${ }^{1}$ \\ 'University of Split, Faculty of Kinesiology, Split, Croatia
}

\begin{abstract}
The article is providing highlights of the 16th Annual International Scientific Conference 'Sport, Physical Activity and Health: Contemporary Perspectives', hosted by the Montenegrin Sports Academy. The event was held on April 4-7, 2019 in Dubrovnik, Croatia. The conference provided space for presentation research papers and related discussion, as well as for poster sessions. Besides welcoming invited speakers it also hosted CEEPUS Training School for students. The participants of the conference were welcomed by Professor Doctor Stevo Popovic, dean of the Faculty for Sport and Physical Education, University of Montenegro, as well as by Dusko Simonovic, president of the Montenegrin Olympic Committee. The conference was officially opened in the large conference hall of the Hotel Croatia in Cavtat by rector of the University of Montenegro, Danilo Nikolic. This prestigious event gathered 364 authors and 223 participants, coming from almost 50 countries.
\end{abstract}

Key words: Scientific Conference, Sports, Physical Activity, Health, Training School

\section{Introduction}

The greatest international event from the area of sports sciences was successfully held in Dubrovnik, Croatia this year. The 16th Annual International Scientific Conference 'Sport, Physical Activity and Health: Contemporary Perspectives' was hosted by the Montenegrin Sports Academy on April 4-7, 2019 in the Hotel Croatia in Cavtat. It has been considered as one of the most important scientific events related to the sports sciences in the region due to its increasing international standing and relevance of the conference that was firmly confirmed as it hosted 364 authors and 223 participants from almost 50 countries.

'This year conference is the most attended conference ever that is organized by the Montenegrin Sports Academy and Faculty for Sport and Physical Education at the University of Montenegro. However, it is interesting that we have just 70 females, comparing to 152 males, but I do believe the Female Investigator Award might distract this trend in the future and promote our annual conference among the female population, said Professor doctor Stevo Popovic, dean of the Faculty for Sport and Physical Education, University of Montenegro.
The conference provided the platform for researchers and experts who had an opportunity for networking through discussions and exchange on the international level. This event gave an opportunity for experts not only to network, but also to share ideas and present their research to a worldwide community.

This year's conference was held with the overwhelming support and acknowledgement from all the partner institutions. The conference chair, Professor doctor Dusko Bjelica, handed them out the certificates of appreciation for the special contribution and support to the conference. The recipients of the certificate in this category were Danilo Nikolic, Dusan Simonovic, Haris Alic, Damir Sekulic, Tomislav Krsticevic, Antonio Figueiredo, Svetislav Popovic, Igor Vusanovic, Velimir Rakocevic, Nikola Milovic, Marin Corluka, Zoran Milosevic, and Nebojsa Maksimovic. The next category was intended for the invited speakers who were also awarded with a certificate of appreciation for outstanding accomplishment in invited speech and the recipients for this category were Michael Chia, Young Sub Kwon, Robert C. Schneider, Milan Zvan, Lana Ruzic, and Miodrag Spasic.

\section{Correspondence:}

Montenegro Sport 


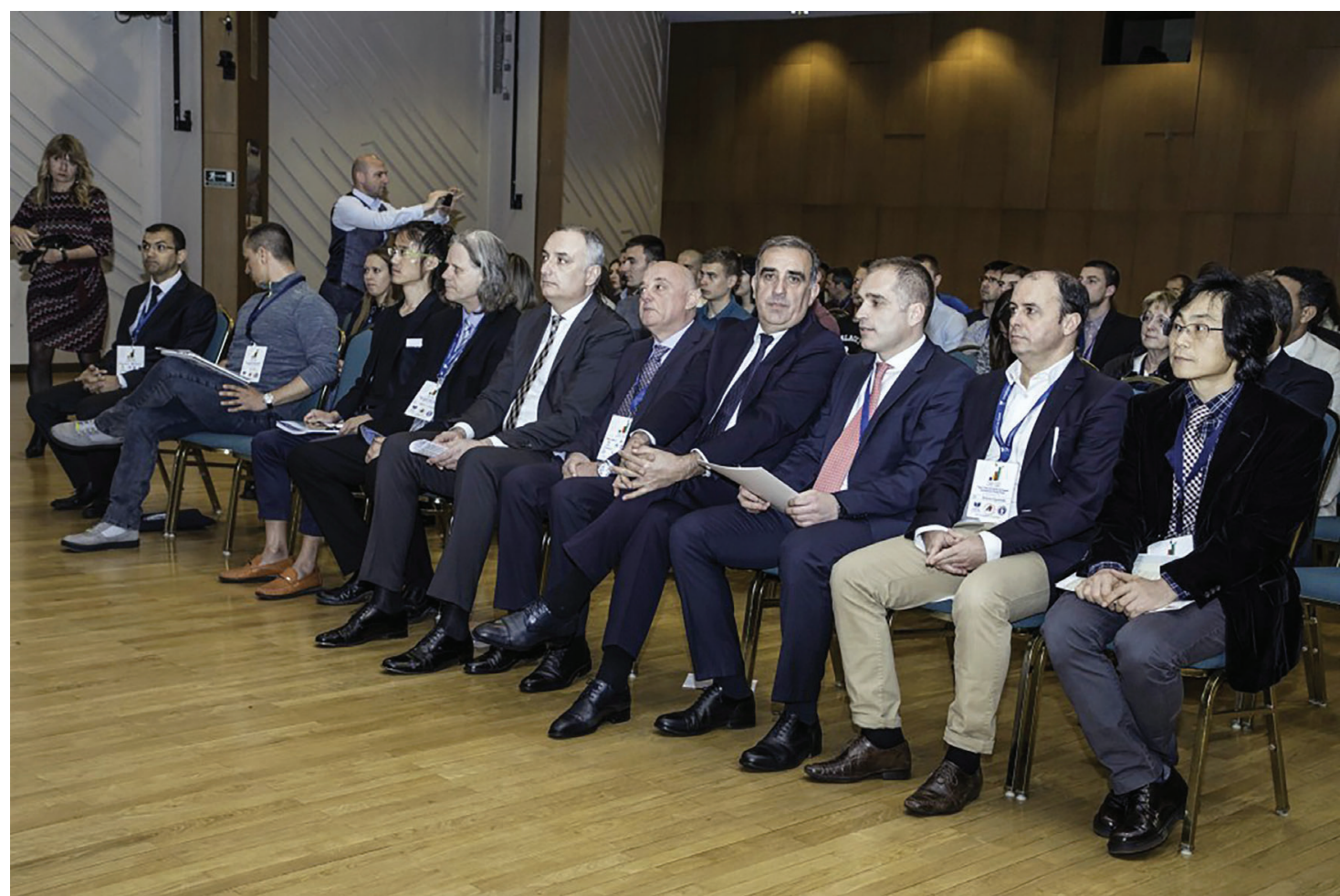

Picture 1. Conference president, chairs of the scientific committee, rector of the University of Montenegro and president of the Montenegrin Olympic Committee

The third awarded category were the workshop chairs who ment in workshop presentation and the recipients were Jose Pedro received a certificate of appreciation for outstanding accomplish- Ferreira, Selcuk Akpinar, Yang Zhang, Ugur Odek, Igor Vusurovic.

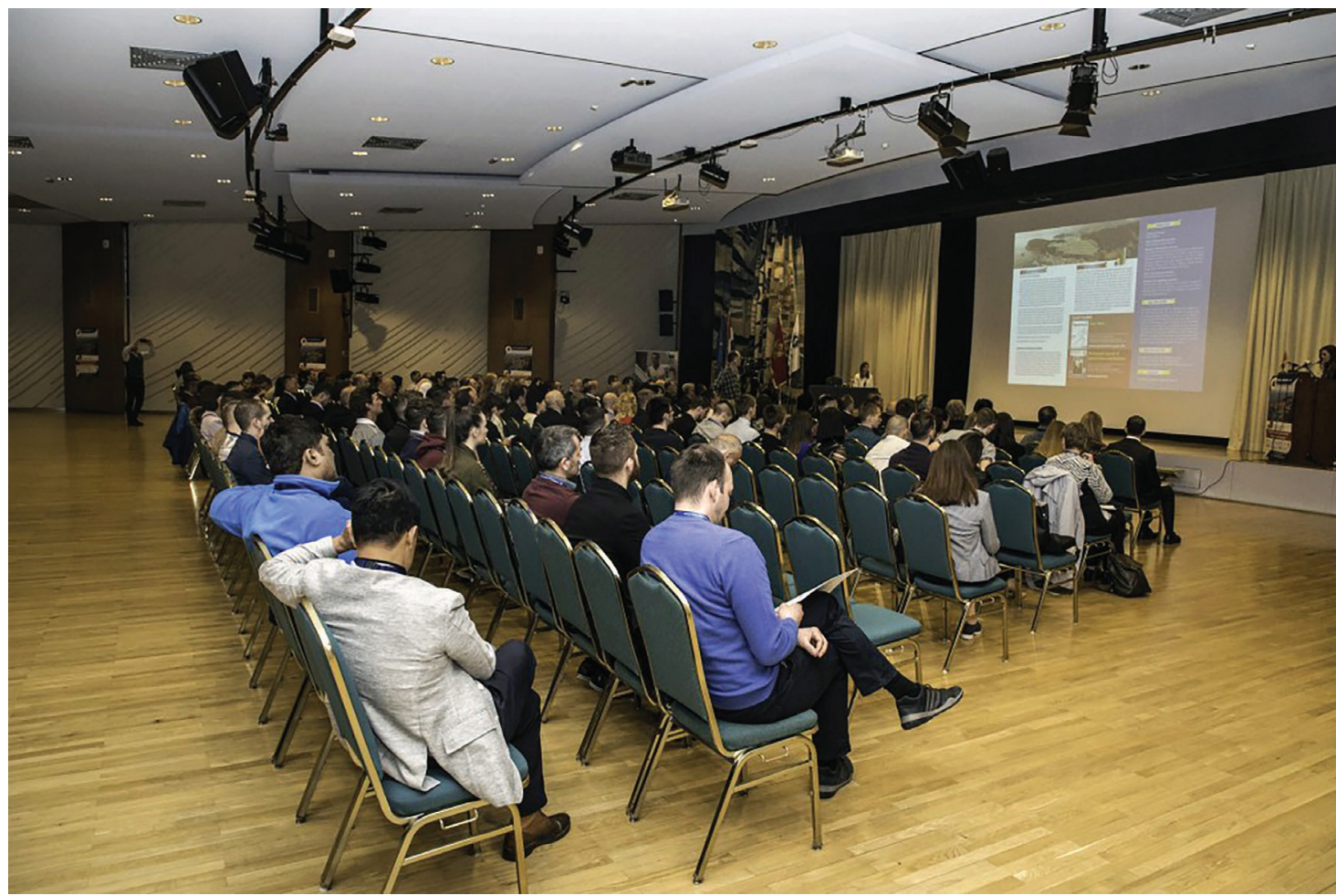

Picture 2. Opening ceremony

This year, as a part of the conference, CEEPUS Training School 'How to prepare, write and publish a scientific paper in sport sciences' has been hosted as well. It provided students with the basis for further research and development as scientists as well as an opportunity for understanding of the com- plex relationships between theoretical and practical issues. The teachers included in this school received a certificate of appreciation for outstanding accomplishment in CEEPUS Training School lectures and these were Sanja Pekovic, Radenko Matic, Bojan Masanovic, Ivana Bavcevic, and Stevo Popovic. 


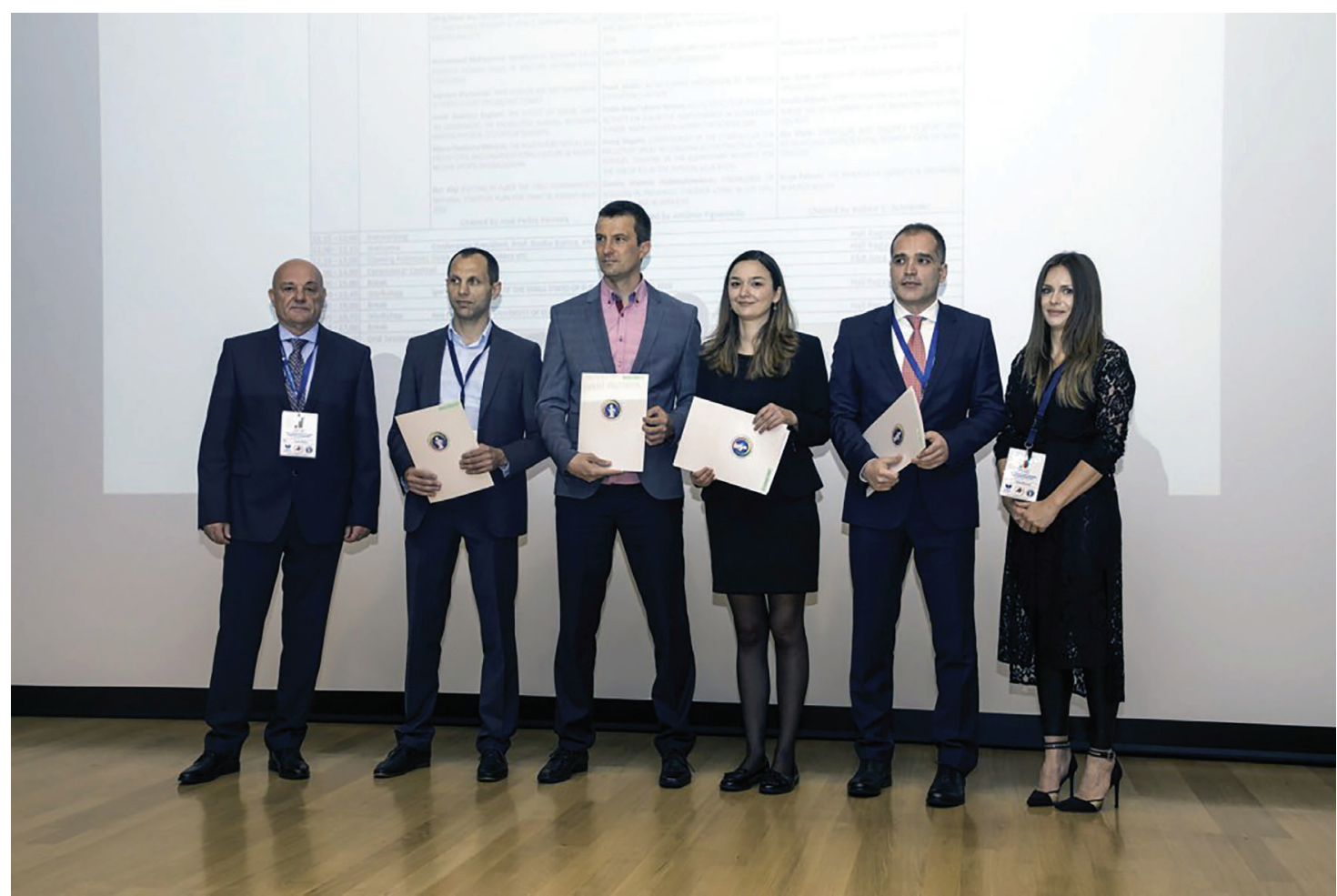

Picture 3. CEEPUS Training School lecturers

The novelty this year were an award for the best female researcher that was conferred to Roselyne Okech, and the one for the best young researcher that was conferred to Dasa Prus.

As the conference was concluded successfully the organisers have already focused on starting the next year's event, and choosing amongst many different venues offered during the networking and collaborating with the fellow experts and partners.

In the words of the conference president Professor doctor Dusko Bjelica, this year's conference has exceeded all the previous expectations as far as the number of participants is concerned as well as the quality of the published papers. 'We are delighted to confirm we have become a brand name in the region as far as the sports sciences are concerned, and therefore we have earned trust from the fellow researchers which has resulted in negotiations for holding the next conference in Antibes, a resort in the French Riviera. For us, this is a great acknowledgment for all the work we have invested so far. We are extremely delighted that people from almost 50 countries recognised not only our efforts, but also the results achieved until now, said Professor Doctor Dusko Bjelica, conference president.

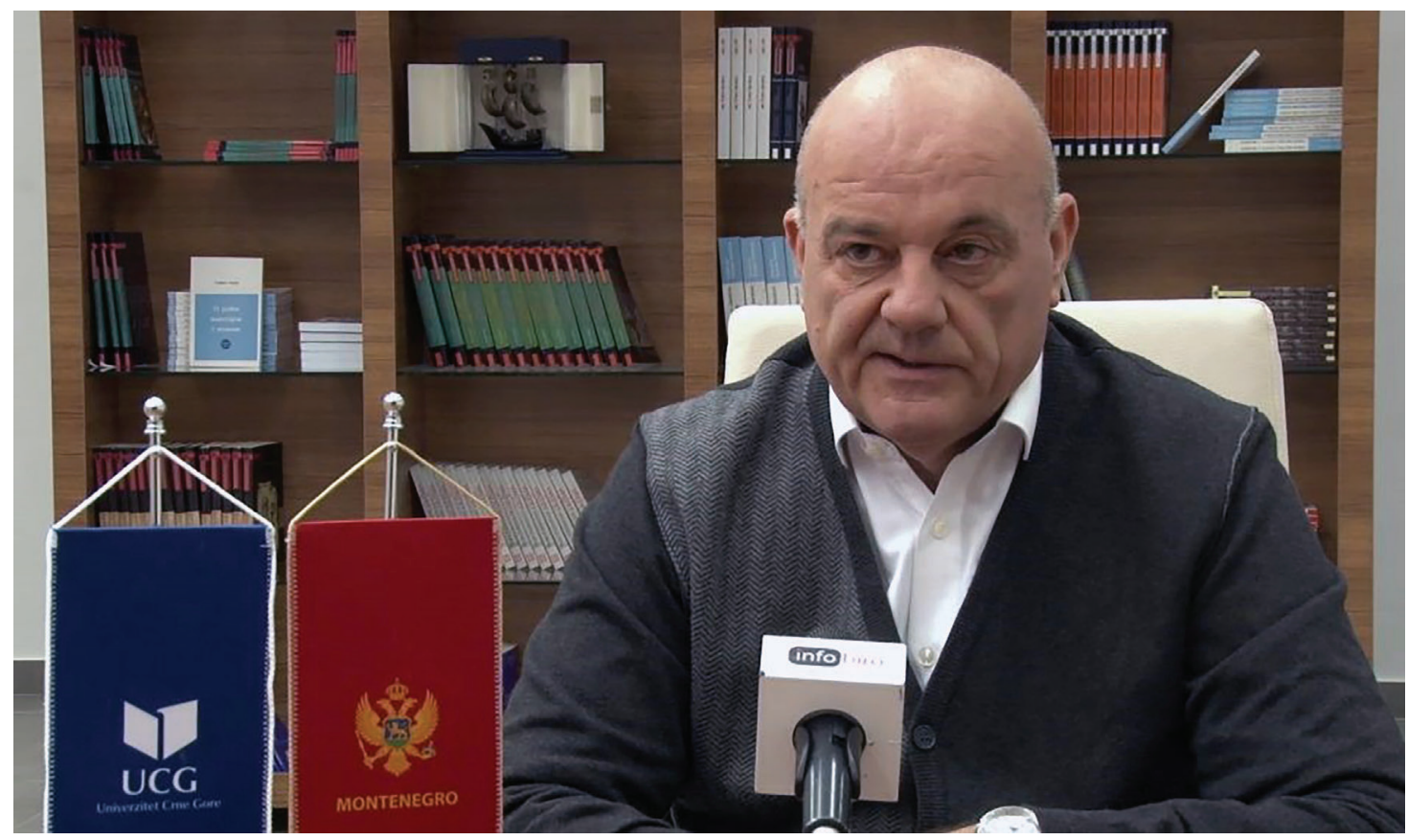

Picture 4. Conference president Professor Doctor Dusko Bjelica 
Acknowledgements

There are no acknowledgements.

\section{Conflict of Interest}

The authors declare that there are no conflicts of interest.

Received: 17 April 2019| Accepted: 29 April 2019| Published: 4 July 2019

\section{References}

Bjelica, D., Popovic, S., \& Akpinar, S. (2014). Book of Abstract of the 11th International Scientific Conference on Transformation Process in Sport 'Sport Performance.' Podgorica: Montenegrin Sports Academy.

Bjelica, D., Popovic, S., \& Akpinar, S. (2015). Book of Abstracts of the 12th International Scientific Conference on Transformation Process in Sport 'Sport Performance.' Podgorica: Montenegrin Sports Academy.
Bjelica, D., Popovic, S., \& Akpinar, S. (2016). Book of Abstracts of the 13th International Scientific Conference on Transformation Process in Sport 'Sport Performance.' Podgorica: Montenegrin Sports Academy.

Bjelica, D., Popovic, S., \& Akpinar, S. (2017). Book of Abstracts of the 14th International Scientific Conference on Transformation Process in Sport 'Sport Performance.' Podgorica: Montenegrin Sports Academy.

Bjelica, D., Popovic, S., \& Akpinar, S. (2018). Book of Abstracts of the 15th International Scientific Conference on Transformation Process in Sport 'Sport Performance.' Podgorica: Montenegrin Sports Academy.

Bjelica, D., Popovic, S., \& Akpinar, S. (2019). Book of Abstracts of the 16th International Scientific Conference 'Sport, Physical Activity and Health: Contemporary Perspectives.' Podgorica: Montenegrin Sports Academy. 